\title{
Casca de café em dietas para vacas em lactação: consumo, digestibilidade, produção e composição de leite ${ }^{1}$
}

\author{
Fernanda Cipriano Rocha ${ }^{2}$, Rasmo Garcia ${ }^{3}$, Acyr Wanderley de Paula Freitas ${ }^{4}$, Alexandre \\ Lima de Souza ${ }^{5}$, Kátia Fernanda Gobbi ${ }^{6}$, Sebastião de Campos Valadares Filho ${ }^{3}$, Rafael \\ Gonçalves Tonucci ${ }^{6}$, Gabriel Cipriano Rocha ${ }^{6}$
}

\author{
1 Projeto financiado pela Fundação de Amparo à Pesquisa do Estado de Minas Gerais (FAPEMIG). \\ 2 Doutora em Zootecnia. \\ 3 Departamento de Zootecnia - UFV. Bolsista do CNPq. \\ ${ }^{4}$ Pólo Regional da Alta Paulista - APTA. \\ 5 Departamento de Ciências Biológicas/Zootecnia - UFMT. \\ 6 Zootecnista, DZO/UFV.
}

RESUMO - Avaliaram-se o consumo, a digestibilidade aparente da dieta, a produção e a composição do leite de vacas recebendo quatro níveis de casca de café na dieta $(0,0 ; 6,0 ; 12,0$ e 18,0\% da MS total) em substituição à silagem de milho na dieta. Foram utilizadas 12 vacas da raça Holandesa, em três quadrados latinos 4 x 4, distribuídas de acordo com o período de lactação. As dietas foram isoprotéicas, com 15,0\% de PB, constituídas de $60 \%$ de volumoso (silagem de milho e casca de café) e $40 \%$ de concentrado, com base na MS. Os consumos de MS, MO, PB, CT, CNF, EE e NDT decresceram linearmente com a adição da casca de café, ao passo que o consumo de FDN aumentou linearmente. As digestibilidades aparentes de MS, MO, PB, CT, FDN e a concentração de NDT das dietas diminuíram linearmente com a adição de casca de café, mas a digestibilidade do EE não foi influenciada pelos níveis desse subproduto na dieta. A produção de leite apresentou comportamento quadrático, com produção máxima estimada de 26,83 kg leite/dia para o nível de 8,44\% de casca de café, que não influenciou os componentes do leite. A casca de café apresentou potencial para ser utilizada em dietas para vacas em lactação, podendo substituir até $12 \%$ da silagem de milho, dependendo da disponibilidade e conveniência econômica.

Palavras-chave: composição bromatológica, resíduo agroindustrial, silagem de milho

\section{Coffee hulls in diets of lactating dairy cows: intake, digestibility and milk yield and composition}

\begin{abstract}
The objective of this trial was to investigate the effect of replacing corn silage with coffee hulls ( 0 , $6.0,12.0$, and $18.0 \%$ of DM) on intake, apparent total tract digestibility of nutrients, and milk production and composition. Twelve Holstein cows were blocked by days in milk and randomly assigned to three replicated $4 \mathrm{x} 4$ Latin squares. Diets were isonitrogenous averaging $15.0 \%$ of $\mathrm{CP}$ and composed by $60 \%$ of forage (corn silage and coffee hulls) and $40 \%$ of concentrate, on DM basis. Intakes of DM, OM, CP, TC, NFC, EE and TDN all decreased linearly while the opposite was observed for neutral detergent fiber (NDF) with the inclusion of coffee hulls in the diet. Apparent total tract digestibilities of DM, OM, CP, TC, and NDF and the dietary TDN content decreased linearly by increasing the proportion of coffee hulls in the diet but no significant effect was observed for EE digestibility. A significant quadratic effect was found for milk yield, with maximum of $26.83 \mathrm{~kg} /$ day at the coffee hulls level of $8.44 \%$. No quadratic effect was observed for milk components. It can be concluded that coffee hulls can replace up to $12 \%$ of the corn silage DM in the diet depending on the availability and economic costs.
\end{abstract}

Key Words: by-product, corn silage, chemical composition

\section{Introdução}

A nutrição de vacas lactantes é feita visando fornecer nutrientes suficientes para suprir as exigências de nutrientes e assegurar o nível de produção almejado. No Brasil, as silagens de milho e sorgo têm sido os volumosos mais utilizados em dietas para vacas leiteiras exploradas em sistema intensivo (Nussio, 1993). A silagem de milho, inclusive, destaca-se por sua alta produtividade e pelo elevado conteúdo energético. Contudo, a produção destes volumosos tem exigido considerável demanda de recursos técnicos e financeiros, tornando necessária a busca por outros tipos de alimentos que reduzam os gastos com alimentação dos animais sem que a produção de leite seja afetada. 
Nesse contexto, os resíduos da agroindústria podem assumir importante papel na alimentação dos ruminantes, principalmente em situações em que a disponibilidade natural de forragens nas pastagens é baixa e as reservas de forragens conservadas são insuficientes para atender às necessidades dos rebanhos, sendo necessário formular misturas múltiplas para animais em pastejo, ou a disponibilidade, o valor nutritivo, o volume produzido e o custo do resíduo permitem sua inclusão em concentrados, substituindo parcialmente os alimentos nobres comumente utilizados (Souza et al., 2004).

A casca de café tem sido um dos resíduos agrícolas mais avaliados na alimentação de ruminantes, principalmente por sua disponibilidade nas regiões produtoras. $\mathrm{Na}$ safra 2002/2003, o estado de Minas Gerais produziu 52\% do café beneficiado no Brasil (ABIC, 2003). No Brasil, o preparo do café é feito por via seca e o subproduto gerado é a casca de café, cujo rendimento pode atingir $50 \%$ do peso na colheita.

No Brasil, estudos têm sido realizados para estabelecer os níveis adequados de casca de café no concentrado para bovinos e ovinos em substituição ao milho ou ao milho desintegrado com palha e sabugo (MDPS). Assim, apesar da grande disponibilidade desse resíduo, ainda são poucas as informações sobre sua utilização em substituição ao volumoso na dieta de bovinos.

Pesquisas têm comprovado a viabilidade técnica e econômica do uso da casca de café em regiões com grande disponibilidade desse resíduo. Segundo Barcelos (1997), a substituição de até $30 \%$ do MDPS pela casca de café em rações para novilhos em confinamento não comprometeu o ganho de peso dos animais e ainda reduziu o custo dos concentrados, o custo diário com alimentação e o benefício diário por animal.

Ao incluírem a casca de café em substituição ao milho no concentrado de vacas em lactação $(0,0 ; 8,75 ; 17,5$ e $26,25 \%$ da MS), Souza et al. (2003a,b) observaram decréscimo no coeficiente de digestibilidade dos nutrientes. O consumo de MS e a produção e composição do leite não foram alterados pelos níveis de casca de café utilizados. Todavia, menor custo com a alimentação e maior margem bruta foram obtidos com os maiores níveis de casca de café. Assim, esses autores recomendaram a inclusão de até $26,25 \%$ deste resíduo em substituição ao milho no concentrado para vacas em lactação, o que representa $10,5 \%$ de casca de café na MS da dieta.

Assim, realizou-se este estudo para avaliar o consumo, a digestibilidade aparente da dieta e a produção e composição do leite de vacas consumindo dietas contendo 0,0 ; 10,0; 20,0 e 30,0 de casca de café (com base na MS) em substituição à silagem de milho.

\section{Material e Métodos}

O experimento foi realizado no Setor de Bovinocultura de Leite do Departamento de Zootecnia da Universidade Federal de Viçosa, MG, no período de 23 de junho a 23 de agosto de 2002. Foram utilizadas 12 vacas da raça Holandesa Malhada de Preto (574,50 kg PV e produção média de 25,0 kg leite/dia), distribuídas em três quadrados latinos $4 \times 4$, balanceados de acordo com o período de lactação de cada animal. Cada período experimental teve duração de 15 dias, os oito primeiros para adaptação e os demais para avaliação do consumo, da digestibilidade e da produção e composição do leite.

Os tratamentos foram constituídos de quatro níveis de casca de café $(0,10,20$ e 30\%, com base na MS) em substituição à silagem de milho, correspondendo aos níveis de $0,6,12$ e $18 \%$ da MS total da dieta. As dietas foram isoprotéicas $(15,0 \% \mathrm{~PB})$ e balanceadas para atender aos requerimentos necessários para produção média de $25,0 \mathrm{~kg}$ de leite/animal/dia (NRC, 2001). O concentrado e a casca de café foram fornecidos misturados à silagem de milho no momento do fornecimento ( $6 \mathrm{~h} 40$ e $16 \mathrm{~h} 30$ ), mantendo-se a relação volumoso:concentrado 60:40 com base na MS. Diariamente, foi realizado o ajuste do fornecimento da alimentação, em função das sobras no cocho, mantidas entre 5 e $10 \%$ do total fornecido. A composição percentual dos ingredientes das dietas encontra-se na Tabela 1.

A casca de café, adquirida da Cooperativa dos Cafeicultores de Guaxupé, uma indústria beneficiadora localizada no sul de Minas Gerais, foi obtida pelo beneficiamento do café por via seca e não sofreu qualquer tipo de processamento ao ser misturada aos outros alimentos. As composições bromatológicas da silagem de milho, da casca de café e do concentrado são apresentadas na Tabela 2 e a composição bromatológica das dietas experimentais, na Tabela 3.

Os animais foram alojados em galpão coberto, com baias individuais do tipo tie stall, providas de piso de borracha, com bebedouro automático e comedouros. As vacas foram ordenhadas mecanicamente, às 6 e 16h, efetuando-se o registro diário da produção de leite. Ao início e final de cada período experimental, após a ordenha da manhã, procedeu-se à pesagem dos animais para avaliação da variação de peso vivo.

Diariamente, antes do fornecimento das dietas, as sobras foram pesadas e, durante os períodos de coleta, amostras dos alimentos e das sobras foram coletadas e acondicionadas em sacos plásticos, devidamente identificados, e armazenadas emfreezerpara análises laboratoriais posteriores. Amostras de leite na $2 \underline{a}$ e $1 \underline{a}$ ordenhas do $12 \underline{o}$ e $13 \underline{o}$ dias, respectivamente, de cada período experimental foram 
Tabela 1 - Proporção dos ingredientes no concentrado, com base na matéria seca

Table 1 - Ingredient composition of the concentrate (\% DM)

\begin{tabular}{lc}
\hline $\begin{array}{l}\text { Ingrediente }(\%) \\
\text { Ingredient }(\%)\end{array}$ & $\begin{array}{c}\text { Concentrado } \\
\text { Concentrate }\end{array}$ \\
\hline Milho (Corn) & 62,96 \\
Farelo de soja (Soybean meal) & 31,6 \\
Uréia $^{1}$ (Urea) & 1,5 \\
Fosfato bicálcico (Dicalcium phosphate) & 1,19 \\
Calcário (Limestone) & 1,82 \\
Sal comum (Salt) & 0,91 \\
Mistura mineral $^{2}$ (Mineral premix) & 0,02 \\
\hline
\end{tabular}

${ }^{1}$ Corresponde à mistura uréia:sulfato de amônia, na proporção de 9:1 (mix of urea and amonium sulfate in the ratio of 9:1).

${ }^{2}$ Composição do premix mineral, \% (composition of the mineral premix): sulfato de zinco (zinc sulfate): 50,00 ; sulfato de cobre (coppersulfate): 41,66 ; sulfato de cobalto(cobaltsulfate): 2,78 ; selenito de sódio (sodium selenite): 2,78 ; iodato de potássio (potassium iodate): 2,78.

Tabela 2 - Composição química e NDT estimados $\left(\mathrm{NDT}_{\mathrm{EST}}\right)$ dos concentrados, da casca de café e da silagem de milho

Table 2 - Chemical composition and estimated TDN of the concentrates, coffee hulls and corn silage

\begin{tabular}{|c|c|c|c|}
\hline $\begin{array}{l}\text { Item } \\
\text { Item }\end{array}$ & $\begin{array}{l}\text { Concentrado } \\
\text { Concentrate }\end{array}$ & $\begin{array}{l}\text { Casca de café } \\
\text { Coffee hulls }\end{array}$ & $\begin{array}{l}\text { Silagem de milho } \\
\text { Corn silage }\end{array}$ \\
\hline $\operatorname{MS}(\%)(D M)$ & 89,02 & 88,13 & 38,51 \\
\hline $\mathrm{MO}^{1}(O M)$ & 92,82 & 92,19 & 95,41 \\
\hline $\mathrm{PB}^{1}(C P)$ & 25,26 & 9,78 & 7,97 \\
\hline $\mathrm{NIDN}^{2}(N D I N)$ & 3,8 & 39,9 & 17,5 \\
\hline $\mathrm{NIDA}^{2}(A D I N)$ & 1,3 & 27,1 & 6,3 \\
\hline $\operatorname{EE}^{1}(E E)$ & 2,75 & 0,87 & 2,5 \\
\hline $\mathrm{CHO}^{1}(T C)$ & 64,54 & 81,54 & 89,94 \\
\hline $\mathrm{FDN}^{1}(N D F)$ & 14,41 & 68,37 & 57,78 \\
\hline $\mathrm{FDN}_{\mathrm{P}}^{1}(N D F p)$ & 13,45 & 64,56 & 56,36 \\
\hline $\mathrm{CNF}^{\mathrm{f}}(N F C)$ & 50,13 & 13,17 & 32,16 \\
\hline $\mathrm{FDA}^{1}(A D F)$ & 28,5 & 59,60 & 32,92 \\
\hline $\operatorname{FDAi}^{1}(i A D F)$ & 0,78 & 45,52 & 14,67 \\
\hline $\mathrm{LIG}^{1}$ (Lignin) & 1,62 & 13,58 & 6,9 \\
\hline $\mathrm{NDT}_{\mathrm{EST}} 1,3(T D N)$ & 83,94 & 48,22 & 63,26 \\
\hline
\end{tabular}

1 Valores em porcentagem da MS (values in DM basis).

2 Valores em porcentagem do nitrogênio total (values as percentage of total nitrogen).

${ }^{3}$ Estimado pelo NRC (2001) (estimated by the NRC, 2001).

coletadas, compostas proporcionalmente ao volume produzido nas ordenhas da manhã e da tarde e imediatamente analisadas.

As coletas de amostras de fezes para determinação da digestibilidade dos nutrientes foram realizadas às $7,9,11$, 13,15 e $17 \mathrm{~h}$ do $9 \underline{\mathrm{o}}$ ao $14 \stackrel{0}{\mathrm{o}}$ dia de cada período experimental, em intervalos de 26 horas. A estimativa da excreção fecal foi feita utilizando-se a fibra em detergente ácido indigestível (FDAi) como indicador, conforme Cochran et al. (1986), com algumas alterações. Neste procedimento, as amostras dos ingredientes do concentrado e do volumoso, das sobras e das fezes, previamente secas e moídas (peneira $1 \mathrm{~mm}$ ), foram acondicionadas em sacos Ankon (Filter bags F57) e incuba-
Tabela 3 - Composição química (valores médios) e NDT estimados $\left(\mathrm{NDT}_{\mathrm{EST}}\right)$ das dietas experimentais

Table 3 - Chemical compositon (average values) and estimated TDN of the experimental diets

\begin{tabular}{|c|c|c|c|c|}
\hline \multirow[t]{2}{*}{$\begin{array}{l}\text { Item } \\
\text { Item }\end{array}$} & \multicolumn{4}{|c|}{$\begin{array}{c}\text { Nível de casca de café } \\
\text { Coffee hulls levels }\end{array}$} \\
\hline & 0 & 6 & 12 & 18 \\
\hline MS\% (DM) & 59,11 & 62,08 & 65,06 & 68,04 \\
\hline $\mathrm{MO}^{1}(O M)$ & 94,41 & 94,18 & 93,99 & 93,79 \\
\hline $\mathrm{PB}^{1}(C P)$ & 15,00 & 15,11 & 15,22 & 15,33 \\
\hline $\mathrm{NIDN}^{2}(N D I N)$ & 7,62 & 8,56 & 9,44 & 10,37 \\
\hline $\operatorname{NIDA}^{2}(A D I N)$ & 4,09 & 5,55 & 6,28 & 7,52 \\
\hline $\mathrm{EE}^{1}(E E)$ & 2,6 & 2,5 & 2,4 & 1,3 \\
\hline $\mathrm{CHO}^{1}(T C)$ & 79,78 & 79,27 & 78,78 & 78,27 \\
\hline $\mathrm{FDN}^{1}(N D F)$ & 40,43 & 41,07 & 41,70 & 42,34 \\
\hline $\mathrm{CNF}^{1}(N F C)$ & 39,35 & 38,15 & 36,95 & 35,75 \\
\hline Lignina $^{1}$ (Lignin) & 4,79 & 5,18 & 5,58 & 5,99 \\
\hline $\operatorname{FDAi}^{1}(i A D F)$ & 9,11 & 10,97 & 12,82 & 14,67 \\
\hline $\mathrm{NDT}_{\mathrm{EST}}{ }^{1,3}(T D N)$ & 71,53 & 70,62 & 69,72 & 68,82 \\
\hline
\end{tabular}

1 Valores em porcentagem da MS (values in DM basis).

2 Valores em porcentagem do nitrogênio total (values as percentage of total nitrogen).

${ }^{3}$ Estimado pelo NRC (2001) (estimated by the NRC, 2001).

das no rúmen por um período de 144 horas. O material remanescente da incubação foi previamente lavado com água e submetido à extração com detergente ácido, cujo resíduo foi considerado FDAi.

As amostras de sobras, fezes e silagem de milho foram secas em estufa ventilada, a $65^{\circ} \mathrm{C}$ por 72 horas, para se proceder à moagem. Os ingredientes da ração e o material seco em estufa foram processados em moinho tipo Willey com peneira de $1,0 \mathrm{~mm}$, acondicionados em vidros com tampas e armazenados para posteriores análises laboratoriais.

As análises de MS, MO, PB, FDN, FDA, LIG, EE, NIDA e NIDN foram feitas segundo os procedimentos descritos por Silva \& Queiroz (2002). Os teores de CT foram calculados segundo as equações propostas por Sniffen et al. (1992), em que CT = 100-(\%PB + \%EE + \%CIN), e os de CNF, pela fórmula $\mathrm{CNF}=\mathrm{CT}-\mathrm{FDN}$.

Nas amostras de leite, analisou-se o teor de NT, segundo procedimentos descritos por Silva et al. (1997). Os teores de sólidos totais foram quantificados pela secagem de amostras de leite em estufa a $105^{\circ} \mathrm{C}$ e os de gordura foram determinados em aparelho modelo MK 2.5. A produção de leite corrigida para $4 \%$ de gordura (PLC) foi obtida pela equação citada pelo NRC (2001), em que: $\mathrm{PLC}=0,4 * \mathrm{PL}+15^{*} \mathrm{G}$ ( $\mathrm{G}=\mathrm{kg}$ de gordura).

As concentrações de NDT $_{\text {EST }}$ dos alimentos, dos concentrados e das dietas totais foram calculadas conforme equações descritas pelo NRC (2001). Os valores de NDT calculados para as diferentes dietas foram obtidos pela equação: $\mathrm{NDT}=\mathrm{PBD}+\mathrm{EED}$ x 2,25 + FDND + CNFD. 
Para análise da economicidade, considerou-se o consumo dos animais, a produção de leite e o preço dos alimentos e do leite. A receita com a produção de leite por vaca foi representada pelo produto entre a produção de leite e o preço do leite, enquanto, a receita/preço por litro de leite foi considerada o preço bruto do leite C pago em 2003 aos produtores de Minas Gerais. O custo com alimentação/vaca foi representado pelo produto dos preços dos alimentos utilizados (silagem de milho, concentrado e casca de café) pelo seu respectivo consumo de matéria natural. A obtenção do custo por litro de leite produzido foi feita dividindo-se os gastos com alimentação por vaca pela produção de leite por vaca. O saldo com alimentação foi obtido pela diferença entre o valor da produção de leite e os gastos com alimentação.

Foram realizadas análises de sensibilidade para determinação do nível de casca de café que maximizou o saldo com alimentação por vaca (NCMS). Para isso, foram feitas simulações com os preços da casca de café, expresso em porcentagem do preço da silagem de milho, que variaram de 20 a 100 (preço relativo), com base na matéria natural. Os valores de NCMS foram calculados igualando-se a zero a derivada das equações de regressão quadráticas do preço relativo da casca, geradas para cada situação.

Os dados foram submetidos às análises de variância e regressão e as variáveis foram interpretadas, a 5\% de probabilidade, utilizando-se o programa SAEG, versão 7.1 (UFV, 1997).

\section{Resultados e Discussão}

Conforme descrito na Tabela 4 , o consumo (kg/dia) de todos os nutrientes, à exceção da FDN, diminuiu $(\mathrm{P}<0,05)$ à medida que a silagem de milho foi substituída pela casca de café.

O consumo de MS (kg/dia) diminuiu 159,9 g/dia para cada unidade (1 kg) de casca de café adicionada. Para o consumo de MS em \%PV e g/kg0,75, estimaram-se valores máximos 3,45 e 169,69 para os níveis de 4,58 e 4,05\% de casca de café na MS total, respectivamente. Os consumos médios diários de casca de café foram de 0,0;1,18;2,33 e 3,07 kg/dia para os animais que receberam as dietas com $0,6,12$ e $18 \%$ de casca na MS da dieta. Esses resultados diferem dos encontrados em outros experimentos, como os realizados por Barcelos (1996) e Souza (2003a), em que os consumos médios na dieta com maior nível de casca de café foram de 1,65 e 1,96 kg/dia. O consumo de matéria seca estimado pelo NRC (2001), no entanto, foi de 20,26 kg/dia, superior ao encontrado neste experimento.

A redução no consumo de MS pode estar associada ao teor da fração fibrosa dos alimentos, pois, embora os teores de FDN das dietas tenham sido próximos (Tabela 3), o teor de lignina da casca de café foi alto $(13,58 \%)$ em relação ao da silagem de milho $(6,9 \%)$, de modo que o teor de lignina da dieta com $18 \%$ de casca foi $20 \%$ maior que o do tratamento controle. Segundo Wilson \& Mertens (1995), a proporção

Tabela 4 - Médias, coeficientes de variação (CV), equações de regressão e coeficientes de determinação $\left(R^{2}\right)$ obtidos para os consumos diários de nutrientes da dieta em função dos níveis de casca de café no volumoso

Table 4 - Means, coefficents of variation (CV), regression equations and coefficients of determination ( $\left.P^{2}\right)$ obtained for the daily nutrient intakes according to different dietary levels of coffee hulls

\begin{tabular}{|c|c|c|c|c|c|c|}
\hline \multirow[t]{2}{*}{$\begin{array}{l}\text { Item } \\
\text { Item }\end{array}$} & \multicolumn{4}{|c|}{$\begin{array}{c}\text { Nível de casca de cafél } \\
\text { Coffee hulls level }\end{array}$} & \multirow[t]{2}{*}{$\mathrm{CV}$} & \multirow[t]{2}{*}{$\begin{array}{l}\text { Equação de regressão } \\
\text { Regression equation }\end{array}$} \\
\hline & 0 & 6 & 12 & 18 & & \\
\hline \multicolumn{7}{|c|}{ Consumo (kg/dia) (Intake, g/day) } \\
\hline $\operatorname{MS}(D M)$ & 20,20 & 19,62 & 19,45 & 17,06 & 6,43 & $\hat{\mathrm{Y}}=20,52-0,1599 \mathrm{X}\left(\mathrm{R}^{2}=0,85\right)$ \\
\hline $\mathrm{MO}(O M)$ & 19,07 & 18,47 & 18,28 & 16,01 & 6,44 & $\hat{Y}=19,36-0,1562 X\left(R^{2}=0,81\right)$ \\
\hline $\mathrm{PB}(C P)$ & 3,34 & 3,13 & 2,96 & 2,48 & 6,05 & $\hat{\mathrm{Y}}=3,39-0,458 \mathrm{X}\left(\mathrm{R}^{2}=0,94\right)$ \\
\hline $\mathrm{EE}(E E)$ & 0,54 & 0,50 & 0,47 & 0,39 & 6,6 & $\hat{\mathrm{Y}}=0,55-0,0081 \mathrm{X}\left(\mathrm{R}^{2}=0,95\right)$ \\
\hline $\mathrm{CT}(T C)$ & 15,37 & 14,91 & 14,81 & 13,00 & 6,54 & $\hat{\mathrm{Y}}=15,61-0,1208 \mathrm{X}\left(\mathrm{R}^{2}=0,90\right)$ \\
\hline $\mathrm{FDN}(N D F)$ & 7,74 & 7,65 & 8,04 & 7,17 & 8,05 & $\hat{Y}=7,65+0,0764 X-0,0055 X^{2}\left(R^{2}=0,62\right)$ \\
\hline $\mathrm{CNF}(N F C)$ & 7,64 & 7,26 & 6,76 & 5,83 & 7,08 & $\hat{\mathrm{Y}}=7,76-0,0985 \mathrm{X}\left(\mathrm{R}^{2}=0,96\right)$ \\
\hline $\mathrm{NDT}(T D N)$ & 14,46 & 12,81 & 11,98 & 10,08 & 9,67 & $\hat{\mathrm{Y}}=14,23-0,2326 \mathrm{X}\left(\mathrm{R}^{2}=0,98\right)$ \\
\hline \multicolumn{7}{|c|}{ Consumo (\% PV) (Intake, \% BW) } \\
\hline $\operatorname{MS}(D M)$ & 3,44 & 3,34 & 3,41 & 2,93 & 8,40 & $\hat{\mathrm{Y}}=3,40+0,0238 \mathrm{X}-0,0026 \mathrm{X}^{2}\left(\mathrm{R}^{2}=0,85\right)$ \\
\hline $\mathrm{FDN}(N D F)$ & 1,32 & 1,30 & 1,42 & 1,23 & 11,08 & $\hat{\mathrm{Y}}=1,32$ \\
\hline \multicolumn{7}{|c|}{ Consumo $\left(\mathrm{g} / \mathrm{kg}^{0,75}\right)\left(\right.$ Intake, $\left.B W^{0.75}\right)$} \\
\hline $\operatorname{MS}(D M)$ & 169,22 & 164,58 & 166,51 & 143,98 & 7,60 & $\hat{\mathrm{Y}}=167,66+1,0063 \mathrm{X}-0,1242 \mathrm{X}^{2}\left(\mathrm{R}^{2}=0,88\right)$ \\
\hline
\end{tabular}

\footnotetext{
${ }^{1}$ Porcentagem de casca de café na dieta (com base na MS).
}

1 Proportion of coffee hulls in the diet (DM basis). 
de parede celular, assim como a resistência do alimento e de suas estruturas fibrosas à quebra durante a mastigação e digestão microbiana, influencia negativamente o consumo . Além disso, Vargas et al. (1982) observaram que a cafeína pode influenciar o consumo e, segundo Cabezas (1976), a presença de níveis superiores a $0,12 \%$ de cafeína provoca efeitos adversos no consumo e na utilização de alimentos por bovinos. É possível que a cafeína, por ser um composto fenólico, aumente a mobilização de ácidos graxos livres para o plasma sangüíneo, ocasionando redução do apetite e do consumo de alimentos (Braham et al., 1973).

A análise de regressão revelou efeito linear dos níveis de casca de café sobre os consumos de MO, PB e EE, estimando-se redução de 156,2; 458,0 e 8,1 g/dia, respectivamente, para cada unidade de casca adicionada. Apesar de as dietas terem sido isoprotéicas, o consumo de PB foi influenciado pelos níveis de casca de café, como resultado da menor ingestão de MS. O consumo de EE, por sua vez, foi influenciado pelo menor consumo de MS e pelo baixo teor de EE na casca de café.

Os consumos de CT e CNF também decresceram linearmente com o aumento dos níveis de casca de café nas dietas, estimando-se, respectivamente, decréscimos de 120,80 e $98,50 \mathrm{~g} / \mathrm{kg}$ de casca adicionada. O consumo de FDN apresentou comportamento quadrático, sendo estimado valor máximo de $8,02 \mathrm{~kg} /$ dia no nível de $6,94 \%$ de casca de café, o que pode estar relacionado ao maior teor de FDN e ao menor conteúdo de CNF da casca de café em relação ao da silagem de milho.

A redução no consumo de NDT com o aumento da participação da casca de café nas dietas pode ser atribuída à redução nos consumos de $\mathrm{CNF}$ e EE (de alta digestibilidade e elevado teor energético), associada ao aumento no consumo de FDN, que, segundo Jung \& Allen (1995), influencia negativamente a disponibilidade dos nutrientes, em virtude de sua lenta e incompleta digestão no sistema gastrintestinal. O consumo de NDT para as dietas com 0 e $6,0 \%$ de casca de café foi maior que o proposto pelo NRC (1989), de 12,18kg/ dia, para vacas com peso médio de $550,0 \mathrm{~kg}$ produzindo $25,5 \mathrm{~kg}$ leite/dia com $4,0 \%$ de gordura.

À exceção do coeficiente de digestibilidade aparente dos CNF, a digestibilidade dos demais nutrientes e o conteúdo de NDT das dietas decresceram linearmente $(\mathrm{P}<0,05)$ com o aumento dos níveis de casca de café nas dietas.

Para os coeficientes de digestibilidade da MS e MO, estimaram-se decréscimos de 0,6052 e 0,5707 unidades, respectivamente, para cada $1,0 \%$ de casca de café adicionada. A redução no consumo de CNF (Tabela 4), nutrientes de disponibilidade rápida e praticamente completa no sistema digestivo de ruminantes (Allen \& Mertens, 1987), associada às diferenças quantitativas entre os constituintes da silagem e da casca de café (Tabela 2), pode explicar essa redução na digestibilidade da MS.

As digestibilidades aparentes de PB e EE decresceram 0,8709 e 0,3849 unidades para cada unidade de casca de café adicionada (Tabela 5). O aumento da fração nitrogenada aderida à parede celular (NIDA e NIDN) das dietas com maiores níveis de casca de café diminuiu a disponibilidade de nitrogênio para os microrganismos ruminais influenciando negativamente a digestibilidade da PB. O baixo consumo de EE e sua reduzida excreção endógena nas fezes podem ter contribuído para a diminuição de sua digestibilidade aparente. Souza et al. (2003b) observaram que esses efeitos se tornaram mais pronunciados à medida que elevaram a quantidade de casca nas dietas.

Estimaram-se reduções de 0,5565 e 0,6934 unidades nas digestibilidade dos CT e da FDN, respectivamente, para cada $1,0 \%$ de casca adicionada. A proporção dos

Tabela 5 - Médias, coeficientes de variação (CV), equações de regressão e coeficientes de determinação ( $\left.R^{2}\right)$ obtidos para os coeficientes de digestibilidade dos nutrientes da dieta em função dos níveis de casca de café no volumoso

Table 5 - Means, coefficents of variation (CV), regression equations, and coefficients of determination ( $P^{P}$ ) obtained for the apparent total tract nutrient digestibilities according to different dietary levels of coffee hulls

\begin{tabular}{|c|c|c|c|c|c|c|}
\hline \multirow[t]{2}{*}{$\begin{array}{l}\text { Item } \\
\text { Item }\end{array}$} & \multicolumn{4}{|c|}{$\begin{array}{c}\text { Nível de casca de café } \\
\text { Coffee hulls level }\end{array}$} & \multirow[t]{2}{*}{$\mathrm{CV}$} & \multirow[t]{2}{*}{$\begin{array}{l}\text { Equação de regressão } \\
\text { Regression equation }\end{array}$} \\
\hline & 0 & 6 & 12 & 18 & & \\
\hline $\mathrm{MO}(O M)$ & 72,42 & 67,09 & 64,12 & 62,00 & 7,25 & $\hat{Y}=71,54-0,5707 x\left(R^{2}=0,96\right)$ \\
\hline $\mathrm{PB}(C P)$ & 74,94 & 68,22 & 63,77 & 59,01 & 7,06 & $\hat{Y}=74,32-0,8709 x\left(R^{2}=0,99\right)$ \\
\hline $\mathrm{EE}(E E)$ & 68,58 & 64,72 & 61,49 & 61,96 & 11,82 & $\hat{Y}=67,65-0,3849 x\left(R^{2}=0,90\right)$ \\
\hline FDN $(N D F)$ & 59,26 & 50,76 & 51,95 & 45,00 & 13,51 & $\hat{Y}=57,98-0,6934 x\left(R^{2}=0,84\right)$ \\
\hline $\mathrm{CNF}(N F C)$ & 85,46 & 87,20 & 78,51 & 82,79 & 7,74 & $\hat{Y}=83,49$ \\
\hline $\mathrm{NDT}(T D N)$ & 71,61 & 65,25 & 61,94 & 59,15 & 9,67 & $\hat{\mathrm{Y}}=70,74-0,6846 \mathrm{x}\left(\mathrm{R}^{2}=0,97\right)$ \\
\hline
\end{tabular}

${ }^{1}$ Valores em porcentagem da MS.

1 Values in DM basis. 
constituintes da FDN (proporção de hemicelulose, celulose e lignina) afeta a digestibilidade da fração FDN (NRC, 2001). Van Soest (1993) relatou que a lignina é o componente mais importante da parede celular secundária que limita a digestibilidade. Antes mesmo de se definir as formas pela qual a lignina se associa aos diferentes componentes da parede afetando a digestibilidade, destaca-se a grande variabilidade na composição da lignina, pois esta fração pode conferir diferentes propriedades nutricionais aos alimentos, tendo em vista os compostos fenólicos que a constituem. As diferenças características entre espécies de plantas, com relação às proporções de lignina, celulose e hemicelulose, resultam em diferentes relações entre lignina e digestibilidade. $\mathrm{O}$ efeito da lignina sobre a digestibilidade depende muito mais de seu efeito direto sobre a digestibilidade da parede celular que sobre a digestibilidade da MO.

A menor digestibilidade dos $\mathrm{CT}$ está relacionada à menor digestibilidade da FDN, em razão dos altos teores de lignina da casca de café (Tabela 2), que limitam a digestão dos polissacarídeos da parede celular no rúmen (Jung \& Allen, 1995). Souza et al. (2001) também observaram baixos valores para a digestibilidade in vitro da FDN (valor médio de 28,9\%).

Existem evidências de que alguns monômeros fenólicos liberados durante a degradação microbiana de materiais fibrosos das plantas podem inibir o crescimento de determinadas bactérias do rúmen e reduzir a digestão da celulose. Segundo Dawson \& Allison (1988), os compostos fenólicos que influenciam a digestão da celulose incluem os ácidos benzóico, cinâmico e caféico.

O conteúdo de NDT diminuiu 0,6846 unidades para cada 1,0\% de casca adicionada (Tabela 5). A redução na digestibilidade aparente da MS e dos nutrientes, somada à menor ingestão de $\mathrm{CNF}$, contribuiu para a redução do conteúdo de NDT das dietas.
As produções médias diárias e a composição do leite dos animais encontram-se na Tabela 6.

A produção de leite foi influenciada $(\mathrm{P}<0,05)$ de forma quadrática pelos níveis de casca de café, estimando-se produção máxima de $26,8 \mathrm{~kg}$ de leite/dia para o nível de $8,44 \%$ de casca de café na dieta. A partir deste nível, a produção de leite pode ter sido limitada pelo consumo de NDT, que foi menor que o sugerido pelo NRC (1989). Por outro lado, Souza et al. (2003a) não observaram influência da casca na dieta de vacas em lactação quando utilizaram até $10 \%$ de casca na dieta total. Os componentes do leite, no entanto, não foram influenciados $(\mathrm{P}>0,05)$ pelos níveis de casca de café nas dietas.

Os animais que consumiram dietas com $0,6,12$ e $18 \%$ de casca de café como volumoso apresentaram variações de 0,$725 ; 0,863 ; 0,512 ;-0,869 \mathrm{~kg} / \mathrm{dia}$ no peso vivo, respectivamente, cujos valores ajustaram-se $(\mathrm{P}<0,05)$ à equação $\hat{\mathrm{Y}}=0,6987+0,1042 \mathrm{X}-0,0105 \mathrm{X}^{2}\left(\mathrm{R}^{2}=0,99\right)$. A partir desta equação, estimou-se que o nível de substituição para que não houvesse variação de peso seria de $14,51 \%$ de casca de café na dieta total.

Os dados relativos aos preços dos insumos e produtos, aos resultados de produção, ao consumo da dieta, ao valor da produção de leite sem e com variação de peso, aos gastos com alimentação, ao saldo com alimentação sem e com variação de peso e aos gastos com alimentação em relação ao valor da produção de leite sem variação de peso encontram-se na Tabela 7.

A inclusão de 6 e $12 \%$ de CC na dieta aumentou o valor da produção de leite (vaca/dia) sem e com variação de peso, refletindo o comportamento observado na produção de leite e na variação de peso. Para o nível de $18 \%$ de inclusão de casca de café, o valor da produção de leite (vaca/dia) sem e com variação de peso foi menor. No entanto, a diferença do nível de $18 \%$ em relação ao de $0 \%$ de CC foi maior quando

Tabela 6 - Médias, coeficientes de variação (CV), equações de regressão e coeficientes de determinação $\left(R^{2}\right)$ para as produções de leite $(P L)$ e os teores de gordura (G), PB, extrato seco total (EST) e extrato seco desengordurado (ESD) em função dos níveis de casca de café no volumoso

Table 6 - Means, coefficients of variation (CV), regression equation, and coefficients of determination ( $P$ P) obtained for milk yield (MY) and contents of fat $(F)$, crude protein (CP), total solids (TS) and solids nonfat (SNF) according to different dietary levels of coffee hulls

\begin{tabular}{|c|c|c|c|c|c|c|}
\hline \multirow[t]{2}{*}{$\begin{array}{l}\text { Item } \\
\text { Item }\end{array}$} & \multicolumn{4}{|c|}{$\begin{array}{c}\text { Nível de casca de café }{ }^{1} \\
\text { Coffee hulls level }\end{array}$} & \multirow[t]{2}{*}{$\mathrm{CV}$} & \multirow[t]{2}{*}{$\begin{array}{l}\text { Equação de regressão } \\
\text { Regression equation }\end{array}$} \\
\hline & 0 & 6 & 12 & 18 & & \\
\hline $\mathrm{G}(\%)(F, \%)$ & 3,75 & 3,89 & 3,87 & 3,95 & 17,50 & $\hat{Y}=3,86$ \\
\hline $\mathrm{PB}(\%)(C P, \%)$ & 3,93 & 3,85 & 3,20 & 3,21 & 3,33 & $\hat{Y}=3,55$ \\
\hline $\operatorname{EST}(\%)(T S, \%)$ & 11,05 & 10,84 & 10,72 & 11,05 & 9,736 & $\hat{Y}=10,92$ \\
\hline
\end{tabular}

\footnotetext{
1 Valores em porcentagem da MS.

${ }^{1}$ Values in DM basis.
} 
Tabela 7 - Receitas, custos com alimentação e saldo obtidos, de acordo com os níveis de casca de café no volumoso Table 7 - Income, costs with feeding and balance according to different dietary levels of coffee hulls

Componentes de receitas, custos e saldos

Income, cost, and balance
Nível de casca de café

Level of coffee hulls

$\begin{array}{lll}0 & 6 & 12\end{array}$

18

1. Preços de produtos e insumos

1. Supplies and products prices

Preço bruto do leite (R $\$ /$ litro $)^{1}$ (Gross milk price, $R \$ /$ liter)

Preço do concentrado $(\mathrm{R} \$ / \mathrm{kg})^{2}$ (Concentrate price, $R \$ / \mathrm{kg}$ )

Preço da silagem de milho $(\mathrm{R} \$ / \mathrm{kg} \mathrm{MN})^{3}$ (Corn silage price, $R \$ / \mathrm{kg} \mathrm{NM}$ )

Preço da silagem de milho ( $\mathrm{R} \$ / \mathrm{kg} \mathrm{MS}$ ) (Corn silage price, $R \$ / \mathrm{kg} D M$ )

Preço da casca de café ( $\mathrm{R} \$ / \mathrm{kg} \mathrm{MN}$ ) (Coffee hulls price, $R \$ / \mathrm{kg} N M$ )

Preço da casca de café ( $\mathrm{R} \$ / \mathrm{kg} \mathrm{MS}$ ) (Coffee hulls price, $R \$ / \mathrm{kg} D M$ )

Preço relativo da casca de café (\% do preço da SM)

Proportional coffee hulls price (\% of corn silage price)

2. Resultados da produção

2. Production data

Produção de leite por vaca (kg/dia) (Milk yield per cow, kg/day)

Variação do peso vivo (Body weight change)

$\begin{array}{llll}24,62 & 26,94 & 26,16 & 24,22 \\ 0,725 & 0,863 & 0,512 & -0,869\end{array}$

3. Consumo médio das dietas (MN)

3. Average dietary intake (fresh matter)

Consumo silagem de milho (kg/dia) (Corn silage intake, $\mathrm{kg} /$ day)

Consumo casca de café (kg/dia) (Coffee hulls intake, $\mathrm{kg} /$ day)

Consumo concentrado (kg/dia) (Concentrate intake, $\mathrm{kg} /$ day)

Consumo total (kg/dia) (Total intake, kg/day)

4. Valor da produção de leite (sem variação do peso vivo)

4. Milk yield gross income (not including body weight change)

Por vaca/dia (R\$/vaca/dia) (Per cow/day, $R \$ /$ cow/day)

Por litro (R $\$ /$ litro) (Per liter, $R \$ /$ liter)

5. Valor da produção de leite (com variação do peso vivo)

5. Milk yield gross income (including body weight change)

Por vaca/dia (R\$/vaca/dia) (Percow/day, R\$/cow/day)

$\begin{array}{lccc}13,123 & 14,485 & 13,478 & 10,061 \\ \hat{\mathrm{Y}}=5,7345 & +0,2391 \mathrm{x}-0,0106 \mathrm{x}^{2}\left(\mathrm{R}^{2}=0,99\right) & \\ 0,533 & 0,538 & 0,515 & 0,415 \\ & & & \\ 6,169 & 5,890 & 5,737 & 4,943 \\ 0,251 & 0,219 & 0,219 & 0,204\end{array}$

Por litro (R $\$ /$ litro) (Per liter, $R \$ /$ liter)

$\begin{array}{llll}31,47 & 27,51 & 24,24 & 18,61 \\ 0,00 & 1,32 & 2,62 & 3,45 \\ 9,08 & 8,82 & 8,74 & 7,67 \\ 40,55 & 37,65 & 35,60 & 29,72\end{array}$

$\begin{array}{llll}11,818 & 12,931 & 12,557 & 11,626\end{array}$

$\hat{Y}=6,9855+0,4276 x-0,0296 x^{2}\left(R^{2}=0,99\right)$

$\begin{array}{llll}0,480 & 0,480 & 0,480 & 0,480\end{array}$

Por litro (R\$/litro) (Per liter, $R \$ /$ liter)

$\begin{array}{llll}0,480 & 0,480 & 0,480 & 0,480 \\ 0,489 & 0,489 & 0,489 & 0,489 \\ 0,055 & 0,055 & 0,055 & 0,055 \\ 0,143 & 0,143 & 0,143 & 0,143 \\ 0,050 & 0,050 & 0,050 & 0,050 \\ 0,056 & 0,056 & 0,056 & 0,056 \\ 39,0 & 39,0 & 39,0 & 39,0\end{array}$

6. Gasto com alimentação

6. Feeding costs

Por vaca/dia (R $\$ / v a c a / d i a)$ (Per cow/day, $R \$ /$ cow/day)

7. Saldo com alimentação sem variação do peso vivo (4-6)

7. Feeding balance not including body weigh change (4-6)

Vaca (R\$/vaca/dia) (Cow, R\$/cow/day)

Leite(R\$/litro) (Milk, R\$/liter)

5,65

0,229

6,95

0,282

8,59

0,319

7,74

0,296

5,11

Leite(R\$/litro) (Milk, R\$/liter)

9. Gastos com alimentação em relação ao valor da produção

9. Expenses with feeding in relation to production gross income

Volumoso (Forage)

Concentrado (Concentrate)

14,6

37,6

52,2

12,2
33,3
45,5

11,7

34,0

45,7

6,82

6,68

0,276

1 Preço médio do leite C recebido pelos produtores de Minas Gerais em 2003.

2 Preços médios dos ingredientes em 2003 em Minas Gerais.

${ }^{3}$ Custos médios do leite produzido na região da Zona da Mata, MG.

1 Average price of type C milk in Minas Gerais (MG), in 2003.

${ }^{2}$ Average price of concentrate ingredients during the year of 2003 in Minas Gerais.

${ }^{3}$ Average production cost of milk producers in the Zona da Mata, MG region. 
se considerou a variação de peso no valor da produção leite, pois o animais nesse tratamento apresentaram variação de peso negativa.

Os gastos com alimentação reduziram linearmente com a inclusão da casca de café na dieta em função do menor preço do kg de MS da casca de café em relação à silagem de milho. No nível de $18 \%$ de casca de café, o menor gasto com alimentação também foi influenciado pelo menor consumo de MS em comparação aos demais níveis. Os saldos com alimentação sem e com VP apresentaram comportamento quadrático (Tabela 7), sendo os pontos de máximo 11,28 e $7,22 \%$ de casca de café, considerando o preço do quilo de
MS da casca de café $40 \%$ do preço do quilo de MS da silagem de milho.

Na Tabela 8 constam as médias dos valores encontrados para o nível de casca de café que maximizou o saldo com alimentação por vaca (NCMS) sem e com variação de peso, em função do preço relativo da casca de café, e respectivas equações de regressão.

Os NCMS apresentaram comportamento linear negativo, com variação de 11,51 a $10,65 \%$ e 7,35 a 6,94\% sem e com variação de peso, respectivamente, com preço do kg de MS da casca de café variando de 20 a $100 \%$ do preço do $\mathrm{kg}$ de MS da silagem de milho. Observou-se baixa sensibilidade

Tabela 8 - Médias dos valores encontrados para o nível de casca de café que maximizou o saldo com alimentação por vaca (NCMS) sem e com variaçao de peso, em função do preço relativo da casca de café, e respectivas equações de regressão

Table 8 - Mean value of the dietary coffee hulls level that maximizes feeding balance per cow including or not body weight change in function of the proportional coffee hulls price

\begin{tabular}{|c|c|c|c|c|c|c|c|}
\hline \multirow[t]{2}{*}{ Item } & \multicolumn{5}{|c|}{$\begin{array}{l}\text { Preço relativo da casca de café } \\
\text { (\% do preço da silagem de milho) } \\
\text { Proportional coffee hulls price } \\
\text { (\% of corn silage price) }\end{array}$} & \multirow[t]{2}{*}{$\begin{array}{l}\text { Equação de regressão } \\
\text { Regression equation }\end{array}$} & \multirow[t]{2}{*}{$\mathrm{R}^{2}$} \\
\hline & 20 & 39 & 60 & 80 & 100 & & \\
\hline NCMS sem variação de peso & 11,51 & 11,28 & 11,27 & 11,05 & 10,65 & $\mathrm{NCMS}=11,74-0,0097 * \mathrm{CC}$ & 0,87 \\
\hline NCMS sem variação de peso & 7,35 & 7,22 & 7,12 & 7,04 & 6,94 & $\mathrm{NCMS}=7,434-0,005 * \mathrm{CC}$ & 0,99 \\
\hline
\end{tabular}

NCMS $=\%$ MS dieta.

do NCMS, sem e com variação de peso, a variações no preço relativo da casca de café, sendo caracterizado pelos coeficientes de inclinação das retas.

Ao avaliarem a utilização da casca de café em substituição ao milho do concentrado, Souza et al. (2003) observaram que as dietas com $26 \%$ de casca de café no concentrado diminuíram o custo com alimentação, reduziram o custo por unidade de leite produzido e resultaram em maior receita, contribuindo para uma margem bruta adicional de $\mathrm{R} \$ 1,23$ em relação à dieta sem casca de café. Em um período de 30 dias, as dietas com 8,$75 ; 17,5$ e $26,25 \%$ de casca no concentrado permitiriam renda adicional de $\mathrm{R} \$ 18,6 ; 24,0$ e 36,9 em relação àquela sem casca de café. Os gastos obtidos com as dietas representaram, em média, 90,5 e 75,3\% da receita proveniente da venda do leite, para as dietas com 0 e $26,25 \%$ de casca de café, respectivamente.

Os altos preços dos alimentos concentrados comumente utilizados na alimentação animal foram os principais res ponsáveis pelos elevados custos das dietas. Portanto, torna-se cada vez mais necessário avaliar alimentos alternativos, como os resíduos da agroindústria, determinando seus níveis de inclusão na dieta, como forma de reduzir o custo da alimentação e, ao mesmo tempo, garantir adequado nível de produção.

\section{Conclusões}

Embora tenha influenciado negativamente o consumo e a digestibilidade da maioria dos nutrientes, a substituição da silagem de milho por casca de café em dietas completas para vacas em lactação com produção de $25 \mathrm{~kg}$ de leite/dia pode ser feita em níveis de até $12 \%$, dependendo da disponibilidade e conveniência econômica.

\section{Literatura Citada}

ALLEN, M.S.; MERTENS, D.R. Evaluating constraints on fiber digestion by rumen microbes. Journal Nutrition, v.118, p.261-270, 1987.

ASSOCIAÇÃO BRASILEIRA DA INDÚSTRIA DE CAFÉ - ABIC. Disponível em: <www.abic.com.br/estat_pagricola.html> Acesso em: 10/03/2003.

BARCELOS, A.F.; ANDRADE, I.F.; Von TIESEHOUSEN, I.M.E. et al. Aproveitamento da casca de café na alimentação de vacas em lactação. In: REUNIÃO ANUAL DA SOCIEDADE BRASILEIRA DE ZOOTECNIA, 33., 1996, Fortaleza. Anais... Fortaleza: Sociedade Brasileira de Zootecnia, 1996. p. $128-130$

BARCELOS, A.F.; ANDRADE, I.F.; Von TIESEHOUSEN, I.M.E. et al. Aproveitamento da casca de café na alimentação de novilhos confinados - resultados do primeiro ano. Revista Brasileira de Zootecnia, v.26, n.6, p.1208-1214, 1997.

BRAHAM, J.E.; JARQUIN, R.; GONZALEZ, J.M. et al. Pulpa y pergamino de café. III. Utilización de la pulpa de cafe en forma 
de ensilaje. Archivos Latinoamericanos de Nutrición, v.23, n.3, p.389-388, 1973.

CABEZAS, M.T. Valor nutritivo de la pulpa de café para ganado de corte. Agricultura en El Salvador, v.3, n.15, p.25-39, 1976.

CHOCHRAN, R.C.; ADAMS, D.C.; WALLACE, J.D. et al. Predicting digestibility diets with internal markers: evaluation of four potential markers. Journal of Animal Science, v.63, p.14761483, 1986.

DAWSON, K.A.; ALLISON, M.J. Digestive disorders and nutritional toxicity. In: HOBSON, P.N. (Ed.) The rumen microbial ecosystem. London: Elsevier Applied Science, 1988. p.445-459.

JUNG, H.G.; ALLEN, S. Characteristics of plant cell walls affecting intake and digestibility of forages by ruminants. Journal of Dairy Science, v.73, n.9, p.2774-2790, 1995.

NATIONAL RESEARCH COUNCIL - NRC. Nutrient requirements of dairy cattle. 6.ed. Washington, D.C.: National Academy Press, 1989. 158p.

NATIONAL RESEARCH COUNCIL - NRC. Nutrient requirements of dairy cattle. 7.ed. Washington, D.C.: National Academy Press, 2001. 381p.

NUSSIO, L.G. Milho e sorgo para a produção de silagem. In: PEIXOTO, A.M.; MOURA, J.C.; FARIA, V.P. (Eds.). Volumosos para bovinos. Piracicaba: Fundação de Estudos Agrários Luiz de Queiroz, 1993. p.75-177.

SILVA, D.J.; QUEIROZ, A.C. Análise de alimentos (Métodos químicos e biológicos). Viçosa, MG: Universidade Federal de Viçosa, 2002. 235p.

SILVA, P.H.F; PEREIRA, D.B.C.; OLIVEIRA, L.L. et al. Físicoquímica do leite e derivados - métodos analíticos. Juiz de Fora: ILCT/EPAMIG, 1997. 190p.

SNIFFEN, C.J.; O'CONNOR, J.D.; Van SOEST, P.J. et al. A net carbohydrate and protein system for evaluating cattle diets: II. Carbohydrate and protein availability. Journal of Animal Science, v.70, n.10, p.3562-3577, 1992.

SOUZA, A.L.; GARCIA, R.; PEREIRA, O.G. et al. Composição químico-bromatológica da casca de café tratada com amônia anidra e sulfeto de sódio. Revista Brasileira de Zootecnia, v.30, n.3, p.983-991, 2001.
SOUZA, A.L.; GARCIA, R.; ROCHA, F.C. et al. Casca de café em dietas de vacas: consumo e produção de leite. In: REUNIÃO ANUAL DA SOCIEDADE BRASILEIRA DE ZOOTECNIA, 40., 2003, Santa Maria. Anais... Santa Maria: Sociedade Brasileira de Zootecnia, 2003a. (CD-ROM)

SOUZA, A.L.; GARCIA, R.; BERNARDINO, F.S. et al. Digestibilidade de dietas com diferentes níveis de casca de café fornecidas para vacas em lactação. In: REUNIÃO ANUAL DA SOCIEDADE BRASILEIRA DE ZOOTECNIA, 40., 2003, Santa Maria. Anais... Santa Maria: Sociedade Brasileira de Zootecnia, 2003b. (CD-ROM)

SOUZA, A.L.; GARCIA, R.; BERNARDINO, F.S. et al. Casca de café em dietas de carneiro: consumo e digestibilidade. Revista Brasileira de Zootecnia, v.33, n.6, p.2160-2176, 2004.

UNIVERSIDADE FEDERAL DE VIÇOSA - UFV. SAEG - Sistema de análises estatísticas e genéticas. Versão 7.1. Viçosa, MG, 1997. 150p. (Manual do usuário).

Van SOEST, P.J. Cell wall matrix interactions and degradationsession synopsis. In: JUNG, H.G., BUXTON, D.R.; HATFIELD, R.D. et al. (Eds.). Forage cell wall structure and digestibility. Madison: American Society of Agronomy, 1993. p.377-393.

VARGAS E.; CABEZAS, M.T.; MURILLO, R. et al. Efecto de altos niveles de pulpa de café deshidratada sobre el crecimiento y adaptación de novillos jóvenes. Archivos Latinoameriacanos de Nutricion, v.32, n.4, p.972-989, 1982.

WILSON, J.R.; MERTENS, D.R. Crop science \& utilization - Cell wall accessibility and cell structure limitations to microbial digestion of forage. Crop Science, v.35, p.251-259, 1995. 